\title{
Research about Training Model of Bed and Breakfast in Remote Mountainous Area
}

\author{
Hao-Xing LIU \\ Management School. Chengdu University of Information \\ Technology \\ CUIT \\ Chengdu, China \\ E-mail: 360703974@qq.com
}

\author{
Ge WEN \\ Management School. Chengdu University of Information \\ Technology \\ CUIT \\ Chengdu, China \\ E-mail: 8829177@qq.com
}

\begin{abstract}
It's one of key points to mountainous area human resource development that practitioners training of Bed and Breakfast ${ }^{1}$ in remote mountainous area. This paper uses both Accurate Judgment theory and Transfer Diffusion theory. Designed a PAT training model which aims at practitioners of $B \& B$. It suggests that we should set training platform, carry out precision, focus on differentiation and transmit grades during practitioners training of $B \& B$ by the method of analyzing the training demand feature of $B \& B$ in remote mountainous area. It's worthy of learning that PAT training model to tourism in remote mountainous area of China. At the same time, it offers a reference to human resource development in remote mountainous area of China.
\end{abstract}

Keywords-Tourism Talent Development; Bed and Breakfast (B\&B); PAT Training Model

\section{INTRODUCTION}

$\mathrm{B} \& \mathrm{~B}$ operation is a form of innovation in tourism industry. It is also a model of industry development transformation in remote mountainous area. B\&B operation solve some problems, such as labor force loss in remote mountainous area and reemployment difficulties. In the long term, B\&B operation have demonstration role in some sides, for instance, effective use for human resource in remote mountainous area, optimization and upgrading of the industrial structure and sustainable development of mountainous area economy. Nevertheless, it has not received the attention deserved in long term for practitioners training of $\mathrm{B} \& \mathrm{~B}$ in remote mountainous area. It restricts further development of mountainous area $B \& B$. Promoting practitioners training level of $B \& B$ can enhance both operation ability and tourism service ability. It also can promote development of B\&B. Therefore, this paper aims at satisfying practitioners training demands for $\mathrm{B} \& \mathrm{~B}$ in remote mountainous area, promoting practice ability and operation ability. By the analysis and research of B\&B operation training model in Niubei mountain, Ganzi Sichuan province. Combine Accurate Judgment theory and Transfer diffusion theory. Proposed a PAT

${ }^{1}$ Bed and Breakfast (B\&B), a kind of family hotel which provides an overnight boardinghouse with breakfast. training model which aim at $\mathrm{B} \& \mathrm{~B}$ in remote mountainous area. The model can solve some problems such as training organizing and management difficulties because of trainer's decentralization, training coverage restricted, training difficulties because of trainer's individual difference, training effect short of the set target. The practitioner's PAT training model of B\&B in remote mountainous area designed by this paper can take a key effect in both mountain human resource improvement and sustainable development of economy.

\section{BACKGROUND ABOUT NIUBEI MOUNTAIN AND B\&B}

Niubei mountainous area is a beautiful place. There are superior nature environment, fresh air and highquality tourism resource. There are some traits in this area such as remote site, high altitude, sparse population, blocked roads and low-level economy development. These traits, widely, exists in South West remote mountainous area. The condition of Niubei mountainous area is a miniature in whole South West mountainous area. To change problems like backward remote mountainous area, low-level economy development and incomplete industrial structure. Using local abundant nature resource and developing tourism industry is effective choice [1].

The word B\&B originated in Western, next introduced into Japan and rise in the eighties in Taiwan. It gradually introduced into China's inland area now. Mountainous area $\mathrm{B} \& \mathrm{~B}$ is a kind of mountainous home-tourism operation unit. It should satisfy some conditions including demands of mountainous area hike or outdoor sport, basing on villagers own buildings, choosing feature by experiencing mountainous area life, having distinctive local custom and atmosphere, pooling of some supporting service such as accommodation, catering, recreation and vocation $^{[2]}$. Owing to service objects aim mainly on tourists who go on a tour alone. Therefore, it's called "the home of tourists" chronically.

Mountainous area B\&B has its inevitability. It universally presents in developed or developing mountainous area tourism place by distinction operation type. Some traits:1.Business entities are mainly 
mountainous area villagers who have part-time behavior; 2.B-E close relationship with the government developments and have strongest mass basis; 3.B\&B have unique local custom and features; 4.The scale operation of $\mathrm{B} \& \mathrm{~B}$ is limited, the level of consumption is limited[3].

B\&B come into being in the development of tourism industry in mountain area. It has important role in the development of tourism industry and changing backward economic outlook in remote mountainous area. First, operation of B\&B solve mass mountainous area residents' reemployment issues; Second, operation of $B \& B$ have become a kind of income way which keeps stable, sustainable and quality; Third, it's important choice that mountainous area industrial structure changing. And it could promote healthy and sustainable development in mountainous area economy.

\section{QUESTIONS OF PRACTITIONERS TRAINING OF B\&B IN NIUBEI MOUNTAIN}

\section{A. Training Organizing Is Difficulty And Training Management Is Complicated.}

According to the statistics, by 2015, there are $61 \mathrm{~B} \& \mathrm{~B}$ in Niubei mountainous area. 32 doors are on the top mountains, 10 doors are on the half, 19 doors are on the foot. Instead by 17 doors compared with 2014. Among these new doors, 11 doors are on the top of hill, 2 doors are out of half, 4 doors are on the foot. By 2015, there are around 410 men operates B\&B in all. They conduct their business on the family as a unit. Among these men, around 340 men are indigenous (accounted $82.92 \%$ of all), around 70 men are outsides (accounted $17.08 \%$ of all). Among these indigenous persons, $272 \mathrm{men}$ are reemployment (accounted $80.00 \%$ of indigenous persons), 48 men used to be a miner or a farmer (accounted 14.11\% of indigenous persons), around 20 men used to be students or a migrant worker (accounted $5.88 \%$ of indigenous persons) [4].

Quantitative change trend chart of Niubei mountainous area is recent years as shown in the table 1 .

TABLE I. QUANTITATIVE CHANGE TREND CHART OF NIUBEI MOUNTAINOUS AREA.

\begin{tabular}{|c|c|c|c|c|c|}
\hline Year & 2012 & 2013 & 2014 & 2015 & 2016 \\
\hline Number & 31 & 34 & 43 & 62 & 68 \\
\hline
\end{tabular}

Native practitioners' structure of $B \& B$ in Niubei mountainous area as shown in the table 2 .

TABLE II. NATURE PRACTITIONERS' STRUCTURE CHART OF B\&B IN NIUBEI MOUNTAINOUS AREA

\begin{tabular}{|c|c|c|c|}
\hline Structure & Returning & Part-time & Re-employment \\
\hline $\begin{array}{c}\text { Number of } \\
\text { People }\end{array}$ & 20 & 48 & 272 \\
\hline
\end{tabular}

As shown in statistics of foregoing, the number of $\mathrm{B} \& \mathrm{~B}$ operation is on the increase in Niubei mountainous area recent years. Commercial premises and practitioners spread in deep mountains and widely persons. Personal structure is complicated and individual difference is great.
All of these conditions led training works difficulties to carry out which from planning to organization and launch. And training management is difficult to carry out.

\section{B. The Educational Level of $B \& B$ Practitioners Is \\ Relatively Low, the Ability to Absorbing And \\ Controlling of Training Content Is Low.}

According to the statistics, among these practitioners, there are around 40 men who are illiterate (accounted $9.76 \%$ of all), around 80 men who have primary school education level (accounted 19.51\% of all), around 190 men who have middle school culture level (accounted $46.34 \%$ of all), around 70 men who have high school culture level (accounted $17.07 \%$ of all), around 32 men who have culture level above high school (accounted 7.80\% of all). As we seen, middle education level are dominate and still have relatively number of illiteracy [5].

Practitioners' education level structure of $B \& B$ in Niubei mountainous area as shown in the table 3.

Table 3 practitioners' education level structure of B\&B in Niubei mountainous area.

\begin{tabular}{|c|c|c|c|c|c|}
\hline $\begin{array}{c}\text { Education } \\
\text { Level } \\
\text { Structure }\end{array}$ & Illiterate & Primary & Middle & High & $\begin{array}{c}\text { Above } \\
\text { high }\end{array}$ \\
\hline $\begin{array}{c}\text { Number of } \\
\text { People }\end{array}$ & 40 & 180 & 190 & 170 & 32 \\
\hline
\end{tabular}

As shown in statistics of foregoing, the education level of $B \& B$ practitioners in Niubei mountainous area stays below high. The education level is relatively low. Besides, the ability to understand new knowledge and skill is limited and training effect is not well.

\section{Practitioners of $B \& B$ Lack of Formal Training Guidance And Competencies Need to Be Improved}

According to study the competency of B\&B practitioners, we survey 10 hostels which from the top and foot. Among them, 7 hostels' practitioners said that they was engaged in agriculture, construction, mining industry before, and never accepted tourism industry staff training. Others, 3 hotels, said that they had accepted several times informal trainings, but training content didn't match the goal. In addition, all of the hostels said they hoped to get more effective help.

Result shows that practitioners of B\&B lack of formal tourism industry guidance and have urgent training demand. Moreover, competencies need to be improved.

\section{THE PAT TRAINING MODEL OF NIUBEI MOUNTAIN B\&B PRACTITIONER}

\section{A. PAT Training Model}

After a systematically analysis of Niubei mountain $\mathrm{B} \& \mathrm{~B}$ practitioners current training model, an improved model which is named "PAT training model" had been designed targeting a series of existing problems in the current training model. 
The PAT training model utilizes "Accurate defining" and "communication diffusion" theories to solve current existing issues, which management difficulties, wide range differences in practitioners, small training coverage area, practitioners not capable of required work and training result below expected, etc. By trying to solve mentioned issues, the PAT training model aims to optimize management, fulfill the needs of individual practitioner, enlarge training coverage and improve practitioners' ability to fit the position. Figure 1 shows the basic theory of PAT training model.

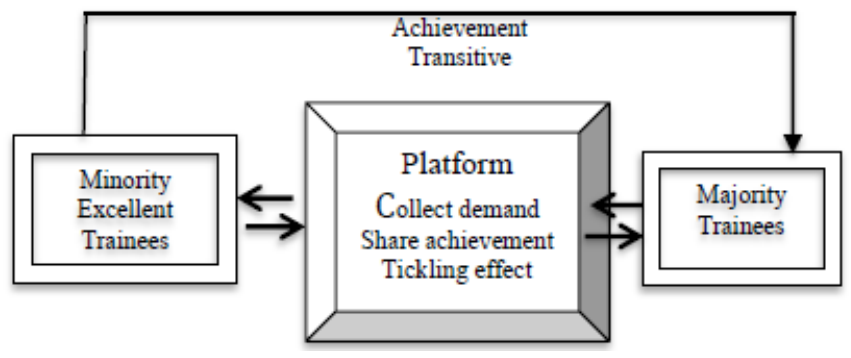

Figure 1. The basic theory of PAT training model

Platform, Accuracy and Transitive_— the key factors of PAT training model.

\section{1) Platform}

Realizing that the training targets are dispersedly located and limited to modern communication tools for organizing in mountainous area, to create a platform for easy communication is urgently needed. The platform is designed using internet as a foundation and use various forms of website or cellphone application to deliver information. Information may include practitioners' info, government departments that are in charge, training group's info, etc. All the information is organized into the Platform for unified organization, implement and management. Users can find training requirement information, training outcome evaluation and feedbacks and even communicate and share experience and resources with other practitioners on the Platform. In the meantime, the Platform provides additional benefits such as advertising, tourists guiding and etc.

\section{2) Accuracy}

Accuracy theory originating from the accurate management model is proposed by the well-known expert in management Xianghuang Cheng [6]. The core idea of accurate theory involves two ideas that are "precision" and "accuracy". "Precision" stands for simplifying procedures, which potentially lowers cost and increase efficiency, which leads to a better outcome. "Accuracy" stands for a clear, well-planed goal, which could help quantifying and organizing steps required toward the goal [7]. It is important to carefully consider practitioners' individual differences, complexities, training total cost and labor cost and practical issue all together to come up with the most suitable Accurate training model.

Accurate training uses well-organized database as a tool to design specific training model for individual. The advantages of this training model are specific, quantified, manageable, low cost and effective and proved useful for individual with different backgrounds and characters.

Niubei mountainous area has many B\&B that are widely distributed over the place with different level of operation capabilities, sizes and goals, needing different and specific guidance and training. To be specific, it is necessary to consider differences in practitioners and use Platform's database combined with mountainous area typical situation and the Accuracy theory all together to come up with the most suitable training plan. For example, for tourism guide type of operators, consider teaching them climbing safety, traffic situation, weather information and climbing preparation training; for dining type of operators, consider telling them more of food safety and mountainous specialty marketing training; for "on the way gas station" type of operator, consider focusing on administrative ability and business etiquette training.

Through survey, we found out two important aspects of Niubei mountainous area $B \& B$ training project are skill training and infrastructure construction. Skill aspect includes: 1. Helping tourism type of practitioners acquiring according tourism certificate; 2 . Self-operation and management training; 3 . Establishing accepted moral values for practitioners; 4. Local culture study; 5. Familiarizing with tourism route and safety education; 6 . Weather predicting skills; 7. Simple outdoor injury treatment skills. Infrastructure construction aspect includes: 1. B\&B decoration; 2. Establishing of Tourism information system and Internet advertisement system; 3. Transforming abandoned mine site into potential tourism site; 4. Building roads and communicating infrastructures like signal towers.

\section{3) Transitive}

Although accurate training fulfills different needs of training individuals and improves practitioners' working ability, it only covers a small targeting area while people generally live widely dispersed in mountainous area. Transitive training utilizes "communication diffusion" theory to solve the mentioned issue [8].

Communication diffusion relies on people as information media. As one person passes information to two people, the two people can then pass information to four others and so on. The theory is based on information carrier's dualism identity, illustrates one typical way of information exchanges. In this case, we will put communication diffusion theory into B\&B practitioners' training model to get basic Transitive training model.

Basically, trained practitioners are expected to become a trainer after fully understood and absorbed major training content. By using oral explanation, written expression or in person illustration, trained practitioners are able to educate untrained personal thus expand training coverage area.

Transitive training model shows its advantages in Niubei mountainous area where B\&B practitioners are widely distributed and $\mathrm{B} \& \mathrm{~B}$ are always operating in unit of family. During the training process according to the different characteristics of participating practitioners, 
introduce "the trained train the untrained" model [9]. Regarding to outstanding practitioners, encourage them to spread their experience and skills among friends, becoming a role of "mentor" to teach more crowds. [10]In this case, the Platform can also be used to spread information and comments of mentors, to encourage communication and provide online class style platform for mentors to use. Applying Platform and Transitive training together can get the best result.

\section{B. The Promotional Value of PAT Training Model}

Niubei mountain B\&B style is typically representative in remote mountainous area, thus PAT training model possesses a potential promotional value which can be illustrated in the following three aspects.

1) Effectively targets issues like "difficulties in management and coordination" and "chaotic management of human resource" typically existed in remote mountainous area and "chaotic management of human resource" typically existed in remote mountainous area.

The core of PAT training model is one unified and harmonious Platform which supports and secures easy quantified management. The Platform connects government departments, training groups, practitioners, informative database and other useful Internet features to solve issue like "management difficulties" and "chaotic human resource management"

2) Fulfills the needs of each individual.

PAT training model advocates accurate training. With the support of adequate database, trainer can quickly get to know an individual and make a targeted training. With training evaluations the model can be adjusted and improved for a more specific targeted training.

3) Effectively increases training coverage area, decreases training cost.

PAT training model effectively decreases cost input by letting "the trained train the untrained". Since practitioners in mountainous area are widely dispersed and sometimes speaking only regional dialogue, Transitive training model is introduced to save cost and increase training coverage. Combining Transitive training with the Platform helps to radiate influence even further.

\section{SUMMARY}

The Niubei Mountain B\&B practitioners training program is not merely a regional issue, but a typical illustration of China remote mountainous region. Thus the PAT training model possesses the potentiality for others to use for reference. Right now, the PAT training model is officially applied in Niubei mountain region, an Internet Platform named "the Home of Niubei Mountains" has been created and a phone APP named Niebei Mountains Tourism has been developed. At the mean time Accurate and Transitive training models program have been combined initiated. However there are some issues such as how to train the trainer; how to attract more users to the Platform; what the best training system is; etc. These are the issues to be considered in the future discussion.

\section{REFERENCES}

[1] Ming Zhong, and Shi Wang, "Analysis about marketing in NiuBei mountainous aera",Rural Tourism. 2013,8:28.

[2] Jie Zhang, "Enlightenment of the farmhouse development in Zhejiang Province",New Rural. 2011,4:34-35.

[3] Chao $\mathrm{Li}$, "the mountianous tourism in Western China ",New Rural. 2012,3:28-29.

[4] "Chinese B\&B market research and investment forecast"China Industry Research Report. 2016:325-326.

[5] "Chinese B\&B market research and investment forecast"China Industry Research Report. 2016:331-332.

[6] Xianghuang Cheng,“accurate management model”5R Management. in press,2003,2:84-87.

[7] Shiqiang Zeng, "the Truth of Management"the Beijing University Press .in press, 2009,5:78-79.

[8] E.M.Rogers, "Diffusion of Innovations" New York : The Free Press.in press, 1983:128-130.

[9] Rosa Mary Yague Perales,'Development Rural Tourism in World". The Geographical Journal,2001,165(2):192- 199.

[10] Cawley M,and Gilmor DA"Integrated rural tourism: Concepts and practice". Annals of Tourism Research,2008,35(2):316-337. 